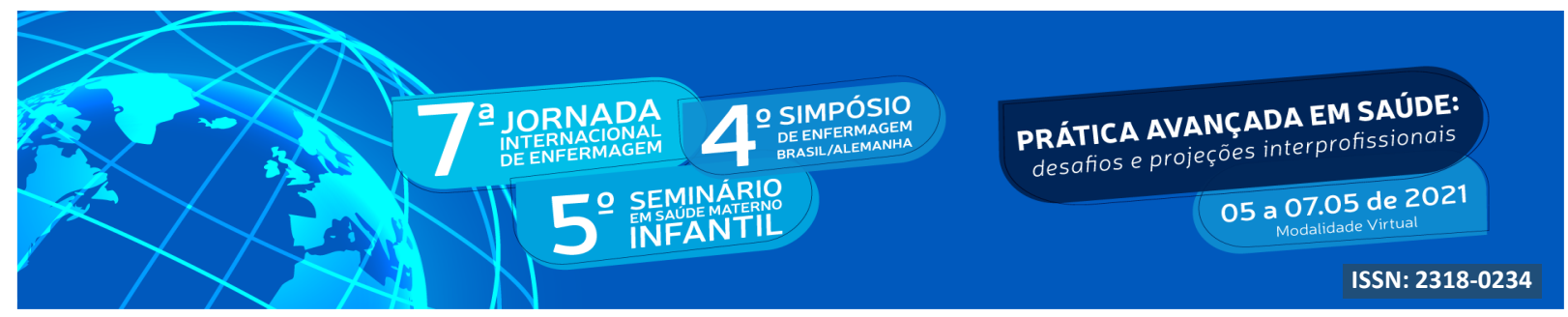

DOI: http://doi.org/10.48195/jie2021-164

\title{
CONTRIBUTOS DA SUPERVISÃO CLÍNICA NA INTEGRAÇÃO DE ENFERMEIROS ${ }^{1}$
}

\author{
Regina Pires $^{2}$; Ana Isabel Carvalho ${ }^{3}$; Margarida Reis Santos ${ }^{4}$
}

\begin{abstract}
RESUMO
Objetivo: Identificar os fatores facilitadores e limitadores do processo de integração dos Enfermeiros recém-admitidos. Método: Estudo qualitativo de caráter exploratório e descritivo, realizado num Hospital do Norte de Portugal, aprovado pelo Conselho de Administração da instituição. Colheita de dados por entrevista semiestruturada. Participaram doze Enfermeiras recém-integradas. Tratamento dos dados através da análise de conteúdo segundo Bardin. Resultados: Da análise dos dados emergiram sete categorias no domínio Fatores Facilitadores da integração e seis no domínio Fatores Dificultadores. Conclusões: O processo de integração dos enfermeiros é determinante para o sucesso da adaptação à organização e para a qualidade do exercício profissional. A estruturação do início da atividade profissional com base na supervisão clínica, potencia o desenvolvimento da autoconfiança no exercício das funções, construção da identidade profissional e desenvolvimento de competências. A identificação dos fatores facilitadores e dificultadores do processo de integração é relevante para o desenvolvimento de processos de integração bem-sucedidos.
\end{abstract}

Palavras-chave: Enfermagem; Integração Profissional; Supervisão Clínica.

\begin{abstract}
Aim: To identify the factors that facilitate and limit the integration process of newly admitted nurses. Method: Qualitative, exploratory and descriptive study, carried out in a Hospital in the North of Portugal, approved by the institution's Board of Directors. Data collection by semi-structured interview. Participated twelve newly integrated nurses. Data treatment through content analysis according to Bardin. Results: From the data analysis, emerged seven categories in the Factors facilitating integration domain and six in the Difficult Factors domain. Conclusions: The nurses' integration process is decisive for the successful adaptation to the organization and for the quality of professional practice. The structuring of the beginning of professional activity based on clinical supervision enhances the development of self-confidence in the exercise of functions, construction of professional identity and development of skills. The identification of factors that facilitate and hinder the integration process is relevant to the development of successful integration processes.
\end{abstract}

Key Words: Clinical Supervision; Nursing; Professional Integration.

\footnotetext{
${ }^{1}$ Estudo qualitativo

${ }^{2}$ Professora Doutora, Escola Superior de Enfermagem do Porto, Portugal, Investigadora do Center for Health Technology and Services Research (CINTESIS). regina@esenf.pt

${ }^{3}$ Enfermeira no Centro Hospitalar Entre Douro e Vouga, E.P.E, Mestre em Supervisão Clínica em Enfermagem. anacarvalho.3@hotmail.com

${ }^{4}$ Professora Doutora, Escola Superior de Enfermagem do Porto, Portugal, Investigadora do Center for Health

Technology and Services Research (CINTESIS).
} 


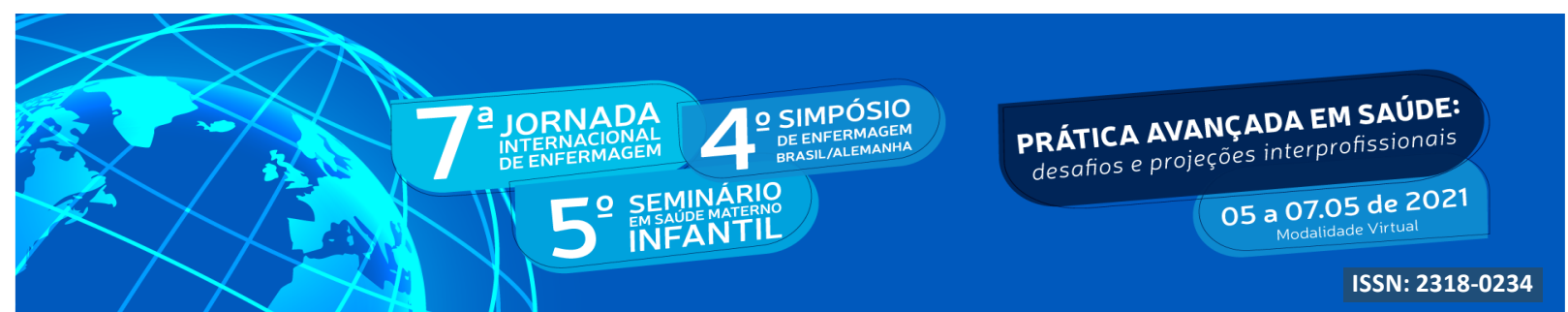

\section{INTRODUÇÃO}

A precariedade dos vínculos contratuais dos enfermeiros, muito devida à contenção de despesa pública e de recursos humanos das instituições de saúde, conduz a grande rotatividade de enfermeiros entre diferentes instituições, e entre serviços da mesma instituição, levando à frequente admissão de novos profissionais (WILLMAN; BJURESÄTER; NILSSON, 2020). Esta realidade exige processos de integração onde se impõe agilidade nas substituições, interferindo com o tempo e conteúdo dos programas de integração. O processo de integração é determinante no sucesso de adaptação do profissional à organização e, consequentemente, no desempenho, uma vez que promove a aquisição de autoconfiança no exercício das suas funções, a construção da sua identidade profissional e o desenvolvimento de competências (AGGAR et al., 2017; WILLMAN; BJURESÄTER; NILSSON, 2020).

As instituições de saúde devem contemplar nas políticas organizacionais, programas de integração orientados para o desenvolvimento das competências dos enfermeiros, cuja operacionalização passa pela supervisão das suas práticas clínicas por profissionais experientes (AGGAR et al., 2017; WILLMAN; BJURESÄTER; NILSSON, 2020).

Pela natureza das suas funções, os enfermeiros necessitam de apoio e suporte contínuo na sua prática, sendo a supervisão clínica amplamente aceite como um requisito essencial na consecussão deste objetivo, através da reflexão, orientação e suporte profissional (AGGAR et al., 2017; WILLMAN; BJURESÄTER, NILSSON, 2020). Os processos supervisivos permitem desenvolver competências profissionais num ambiente de aprendizagem reflexiva, aumentar a eficácia clínica, melhorar os padrões de qualidade dos cuidados por via da prática baseada na evidência e da inovação na prática clínica, assegurando a proteção dos interesses dos clientes, sendo também considerados um direito de todos os profissionais (AGGAR et al., 2017; WILLMAN; BJURESÄTER, NILSSON, 2020; PIRES et al., 2021).

\section{OBJETIVOS}

Identificar os fatores facilitadores e limitadores do processo de integração dos Enfermeiros recém-admitidos. 


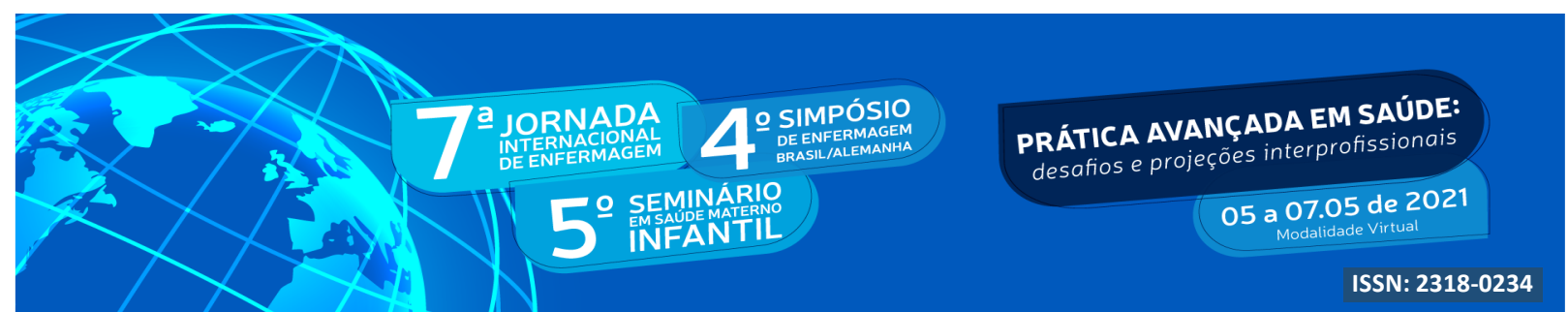

\section{METODOLOGIA}

Atendendo à natureza da problemática em análise, optou-se por uma abordagem qualitativa, realizando-se um estudo exploratório e descritivo, do tipo transversal. O estudo decorreu num hospital do Norte de Portugal. Amostra não probabilística intencional constituída por 12 Enfermeiras. Critérios de seleção dos participantes: ter sido integrado no serviço durante o último ano; não ter experiência anterior em serviço hospitalar idêntico.

A colheita de dados foi realizada através de entrevista semiestruturada. O princípio da saturação dos dados esteve na base da decisão de terminar a colheita de dados. As entrevistas foram gravadas em suporte áudio e posteriormente transcritas na íntegra para suporte informático, respeitando a fidelidade ao discurso.

Os dados foram submetidos a análise de conteúdo segundo Bardin (2011). Foi efetuada uma leitura flutuante, seguida de leituras mais meticulosas, constituindo-se o corpus de análise. Concluída a seleção das unidades de análise, procedeu-se à sua codificação e posterior agregação em domínios e categorias.

O estudo obteve o parecer favorável Conselho de Administração da instituição onde decorreu o estudo (CA-073/15-12, FS/AC). Todas as participantes assinaram voluntariamente o termo de consentimento informado, de acordo com a Declaração de Helsínquia da Associação Médica Mundial e a Lei da Proteção de Dados Pessoais (Decreto-Lei n. ${ }^{\circ}$ 67/98 de 26 de Outubro).

\section{RESULTADOS}

As participantes do estudo foram 12 enfermeiras, do sexo feminino, das quais, três exerciam funções no serviço de Cirurgia Geral, duas no de Medicina Interna, duas no Bloco Operatório, duas na Unidade de Cuidados Intensivos Polivalente e três na Urgência Geral. A idade das participantes variou entre 27 e 37 anos, sendo a média de idades 29 anos. Quanto às habilitações académicas, todas possuíam o Curso de Licenciatura em Enfermagem e uma o grau de mestre. No que respeita às habilitações profissionais, três possuíam um Curso de Especialização em Enfermagem Médico-cirúrgica e uma em Enfermagem de Reabilitação. O tempo de experiência profissional variou entre 2 e 16 anos, sendo a média 5,7 anos. 


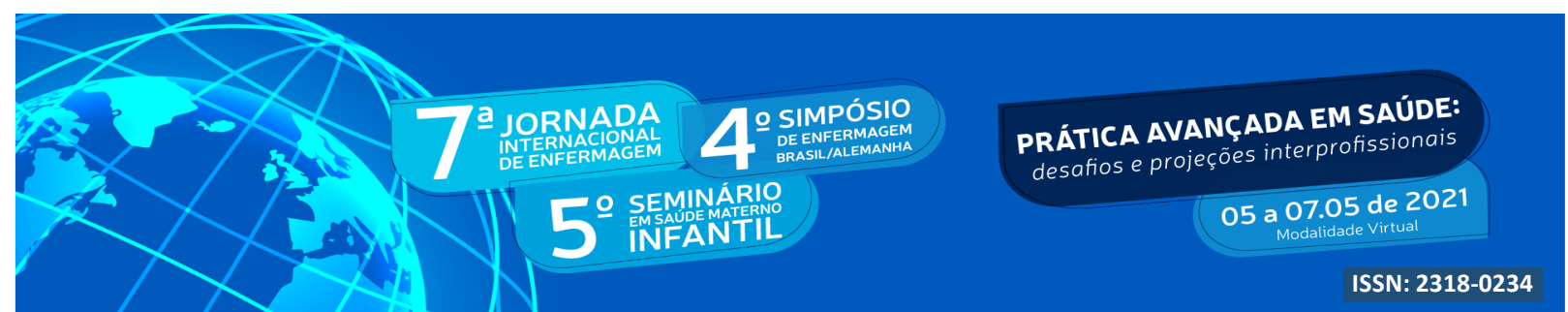

Pediu-se às participantes que refletissem sobre o processo de integração que vivenciaram. Da análise do discurso emergiram dois domínios: Fatores Facilitadores e Fatores Dificultadores. No domínio Fatores Facilitadores emergiram sete categorias (Quadro 1).

Quadro 1: Fatores Facilitadores da Integração

\begin{tabular}{c|l} 
DOMÍNIOS & \multicolumn{1}{c}{ CATEGORIAS } \\
\hline & $\begin{array}{l}\text { Experiência Profissional Anterior } \\
\text { Formação Pós-graduada e Contínua }\end{array}$ \\
$\begin{array}{c}\text { Fatores } \\
\text { Facilitadores }\end{array}$ & $\begin{array}{l}\text { Recetividade/Acolhimento por parte da Equipa } \\
\text { Características do Supervisor }\end{array}$ \\
& $\begin{array}{l}\text { Disponibilidade do Supervisor e da Equipa } \\
\text { Motivação Pessoal }\end{array}$ \\
& Observação Prévia de Técnicas
\end{tabular}

No domínio Fatores Dificultadores do processo de integração emergiram seis categorias (Quadro 2).

Quadro 2: Fatores Dificultadores da Integração

\begin{tabular}{c|l}
\hline DOMÍNIOS & \multicolumn{1}{c}{ CATEGORIAS } \\
& Inexistência de Plano de Integração \\
\hline \multirow{2}{*}{$\begin{array}{c}\text { Fatores } \\
\text { Dificultadores }\end{array}$} & Gestão do Horário \\
& $\begin{array}{l}\text { Inexperiência na Área } \\
\text { Inexistência de Supervisor }\end{array}$ \\
& Duração do Processo de Integração
\end{tabular}

\section{DISCUSSÃO}

O processo inicial de integração e a adaptação a um novo serviço ou o início da atividade profissional está associado a sentimentos de stresse e insegurança, relacionados com as novas atividades que precisam de ser desenvolvidas, conhecimentos que necessitam de ser aprofundados, o trabalhar com pessoas desconhecidas e que, por vezes, adotam posturas intimidantes de avaliação, procurando mesmo falhas no planeamento e execução das 


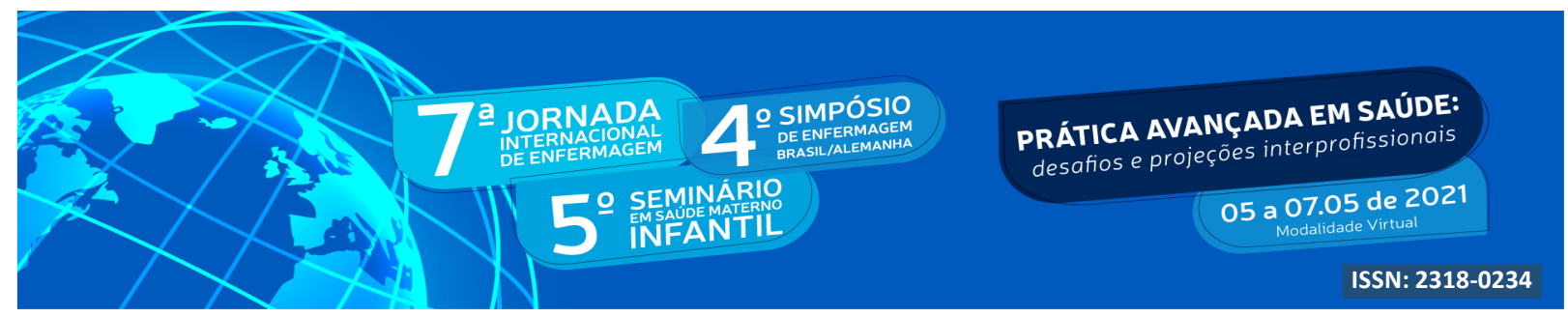

atividades do elemento recém-admitido (WILLMAN; BJURESÄTER, NILSSON, 2020).

Intrínseco às vivências do processo de integração, as participantes consideraram a Experiência Profissional Anterior como um fator facilitador da sua integração: “(...) tinha experiência prévia em serviço de urgência (...) pelo que a integração acabou por ser facilitada (...).” E1. Vários autores referem que a experiência emerge da aprendizagem proporcionada pelos momentos formativos decorrentes da prática, influenciando a perceção da autonomia profissional (WILLMAN; BJURESÄTER, NILSSON, 2020).

As participantes atribuíram ênfase à Formação considerando-a essencial para o desenvolvimento profissional: "Ter especialidade ajudou sem dúvida (...)." E11; "As formações em serviço que fui fazendo foram um aspeto facilitador, pelos contributos ao nível dos conhecimentos o que ajuda na progressão e desenvolvimento profissional." E12. A formação dos enfermeiros é um dos pilares na dinâmica do desenvolvimento pessoal e profissional, sendo um requisito necessário e essencial para garantir a qualidade dos cuidados de enfermagem prestados aos utentes e comunidade (INTERNATIONAL COUNCIL OF NURSES [ICN], 2014).

A Recetividade/Acolhimento por parte da equipa, foi um fator valorizado pelas participantes: “(...) senti que estavam despertos para as minhas necessidades, o que me colocou à vontade para expor as minhas dificuldades e procurar ajuda sem receios.” E4; “A interajuda dos colegas foi indispensável neste processo e ter sido bem-recebida também foi muito importante.” E5. Pinheiro (2012) refere que ser bem acolhido no hospital e na equipa de enfermagem, irá repercutir-se em todo o processo e no desempenho profissional, dado que o processo de integração é um período crítico e fulcral para o bem-estar pessoal e satisfação profissional. Willman, Bjuresäter e Nilsson (2020) referem que o apoio aos colegas recémformados é determinante no desenvolvimento das suas competências e que os que não se mostram interessados em compartilhar os seus conhecimentos e experiências fornecem uma supervisão inadequada, causando níveis aumentados de stresse e deficits de aprendizagem que podem resultar no deficiente atendimento do cliente.

As participantes sugeriram também, como fator facilitador do processo de integração, as Características do Enfermeiro Supervisor: "A enfermeira chefe escolheu um dos colegas mais antigos e com maior experiência na integração para fazer a minha integração, o que facilitou bastante (...) é muito importante ter alguém que sabe, que tem conhecimentos e 


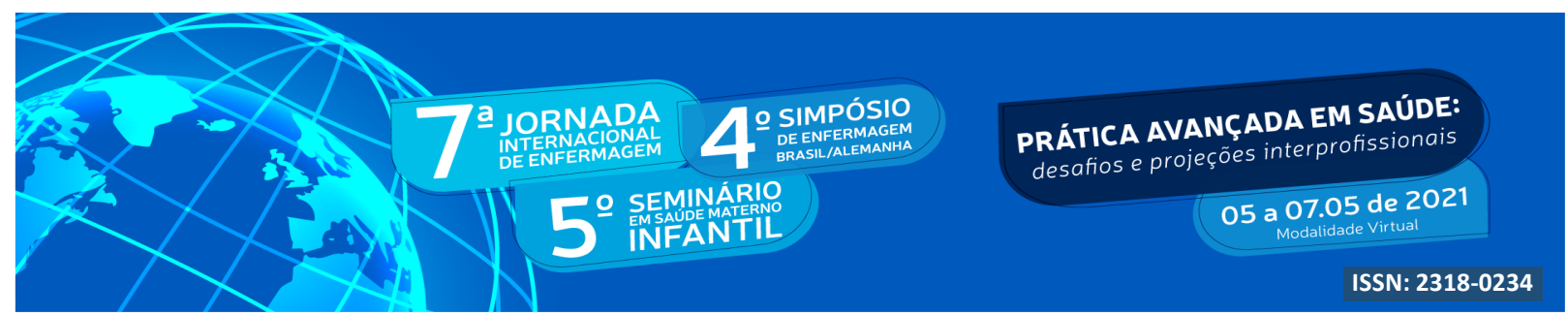

formação (...).” E6. Esta opinião corrobora diferentes estudos que concluíram que o sucesso na integração depende das qualidades ou características do integrador e que a experiência é uma das caraterísticas essenciais nos enfermeiros responsáveis pela integração dos novos colegas (AGGAR et al. 2017; WILLMAN; BJURESÄTER; NILSSON, 2020).

Disponibilidade do Supervisor e da Equipa, foi considerada fundamental para a adaptação dos novos enfermeiros ao serviço: "A disponibilidade e empenho demonstrado pela colega que me integrou e pelos restantes colegas do serviço, foi bastante facilitador (...)." E7. A disponibilidade e o apoio demonstrados pelos colegas e a presença de um orientador fixo (supervisor) são fatores externos responsáveis pela satisfação e sucesso do processo de integração (AGGAR et al., 2017; WILLMAN; BJURESÄTER; NILSSON, 2020).

Motivação Pessoal para Integrar o Novo Serviço foi outra categoria que emergiu do discurso das participantes como fator facilitador do processo de integração: "A mudança para este serviço foi por vontade própria, o que facilitou um bocadinho na integração (...) dado a minha motivação em vir para cá.” E6; “(...) facilitou muito a motivação com que vim para cá, pois era um serviço onde gostaria muito de trabalhar (...)." E8. O sucesso do desempenho profissional depende diretamente da auto-implicação das pessoas envolvidas, do seu comprometimento e da sua motivação. Os fatores que estimulam os indivíduos a fazerem algo estão relacionados com uma hierarquia de necessidades e um impulso para a satisfação, que visa geralmente o crescimento e desenvolvimento pessoal (SOUZA, 2011).

A Observação Prévia de Técnicas foi considerada uma mais-valia ao nível da consolidação de saberes e revisão de alguns conceitos e procedimentos: "(...) sempre que havia a oportunidade de observar alguma técnica menos comum, os colegas davam-me a oportunidade de poder observar e explicavam-me tudo.” E11; “(...) para começar a perceber as dinâmicas do serviço e qualquer coisa que aparecesse de diferente os colegas chamavamme para observar (...) ir participando e observando foi uma mais-valia (...).” E12. A construção dos saberes advém em grande parte da experiência clínica, da observação, da reflexão sobre a prática que exige um permanente vaivém, um diálogo nos processos de interpretação, visando o autodesenvolvimento profissional (SANTOS, 2009). Oliveira (2010) refere que a aprendizagem por observação do comportamento de outros e das suas consequências promove a integração do conhecimento e competências através da informação veiculada por influências de modelação, pois os comportamentos e atitudes vão ser imitados 


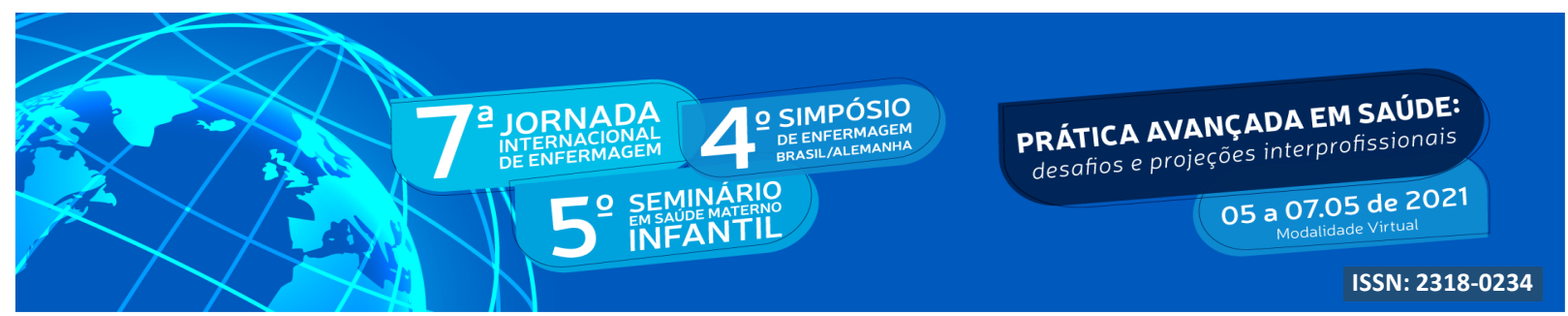

pelos recém-admitidos, convertendo-se em fontes de informação para as crenças de autoeficácia, influenciando o seu desempenho.

Do domínio Fatores Dificultadores do processo de integração emergem as categorias: Inexistência de Plano de Integração, Escassez de Recursos Humanos, Gestão do Horário, Inexperiência na Área, Inexistência de Supervisor e Duração do Processo de Integração.

Pelos testemunhos das participantes verificou-se que não existia nos serviços um plano de integração de enfermeiros: “(...) no serviço não temos nenhum programa que preveja o cumprimento de alguns objetivos e atividades que supostamente se deviam desenvolver ao longo do tempo em que estamos em integração (...)" E9; "Não considero que exista um verdadeiro processo de integração (...) nem sequer há nenhum guia formal de acolhimento no serviço (...)" E10. Esta é uma realidade transversal a muitos dos serviços de saúde, nomeadamente em países com sistemas de saúde mais evoluídos, a argumentando-se a necessidade da implementação de programas de integração para enfermeiros recém-formados e para para os que transitam entre serviços (AGGAR et al., 2017; WILLMAN; BJURESÄTER, NILSSON, 2020). A existência de um programa de acolhimento numa organização permite que o novo elemento assimile, o mais rapidamente possível, a sua cultura e se comporte como um membro dessa organização (MARRINER, 2009).

A Gestão do Horário realizada pela Enfermeira chefe, foi considerada dificultadora da integração e adaptação no serviço, pela sobrecarga horária imposta desde o início: “(...) a carga horária que tinha, por vezes ficava difícil chegar a casa e ainda ir estudar (...).” E3. Willman, Bjuresäter e Nilsson (2020) também concluíram que é responsabilidade dos órgãos de gestão garantir que a dotação de pessoal é adequada para responder ao acompanhamento dos enfermeiros recém-formados em integração, nomeadamente durante os períodos em que muitos membros da equipe estão de férias.

A Escassez de Recursos Humanos foi outra das categorias que emergiu como barreira ao processo de integração efetivo e estruturado: "A falta de profissionais, como não havia elementos para assegurar os cuidados do colega que ficou de baixa, tive de ser eu a assumir (...) tive de ficar logo como elemento integrado na equipa (...).” E5. O ICN (2019) reconhece que atualmente os sistemas de saúde enfrentam dificuldades com a escassez de enfermeiros devido a mudanças geracionais dos provedores de saúde, condições de trabalho insatisfatórias, cargas de trabalho não razoáveis que frequentemente resultam em 


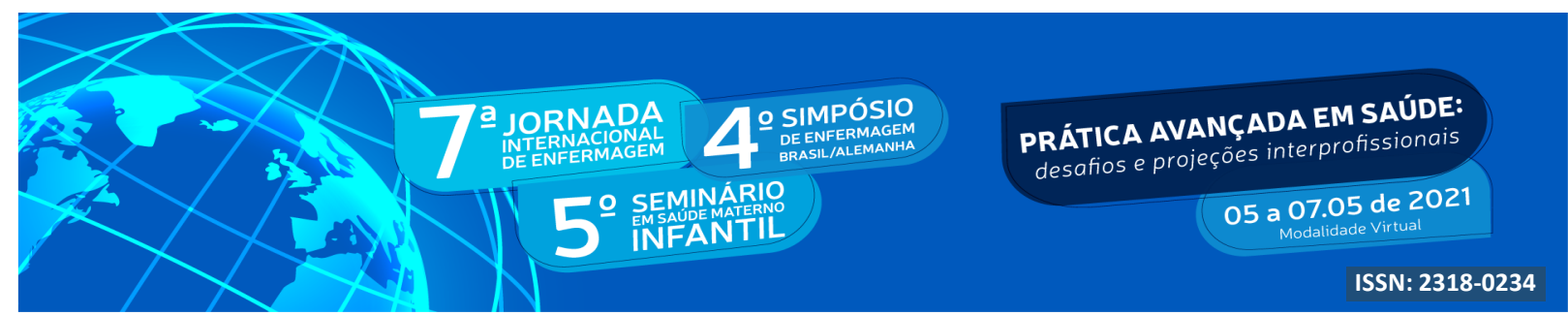

esgotamento, levando ao aumento da rotatividade e ao abandono da profissão nos primeiros anos de vida profissional. Os estudos de Aggar et al. (2017) e de Willman, Bjuresäter e Nilsson (2020) também revelam que a falta de enfermeiros nos cuidados de saúde primários e hospitalares, respetivamente, tem implicações na integração dos novos enfermeiros. Willman, Bjuresäter e Nilsson (2020), mencionam e a necessidade de reter nos serviços os enfermeiros mais experientes de cuidados intensivos, sendo imprescindível uma abordagem abrangente e uma forte liderança de enfermagem e dos gestores hospitalares para descobrir o que os profissionais precisam para ficar, o que pode incluir aspetos como planos de carreira estimulante, maior remuneração e/ou melhores condições de trabalho.

A Inexperiência da área do novo serviço, foi considerada um fator limitador do processo de integração, sobretudo, pela escassez de conhecimentos: "Não ter experiência anterior na área, pode ter sido um pouco limitador no início, porque algumas coisas eram desconhecidas." E11.

As enfermeiras referiram, que embora se propiciassem interações entre colegas num sentido de supervisão ou discussão das práticas, estas não estavam assentes num processo formal com critérios pré-estabelecidos, o que levou a uma descontinuidade da supervisão realizada, pelo que emergiu a subcategoria Inexistência de Supervisor: "Não tive nenhum colega específico a integrar-me. Cada dia ficava com um dos colegas mais velhos (...).”E2; “(...) ter sido orientada por vários colegas, foi por vezes dificultador (...) para quem está a começar a entrar torna-se complicado.” E3. A definição de um elemento (supervisor) responsável pela integração do enfermeiro recém-admitido é muito relevante, uma vez que tal, proporcionará um clima de maior confiança e estabilidade ao enfermeiro em integração, favorecendo a continuidade e uniformidade no acompanhamento (WINSTANLEY; WHITE, 2014). O estudo de Willman, Bjuresäter e Nilsson (2020) revelou que a supervisão e apoio dos colegas é vital para o desenvolvimento profissional dos enfermeiros em integração, para a aquisição das habilidades necessárias para lidarem com as responsabilidades do trabalho, aquisição de competências reflexivas e clínicas e para a qualidade do atendimento. Quando não há continuidade no processo de supervisão ou quando alguns profissionais não estão interessados em compartilhar os seus conhecimentos e experiências com os colegas em integração, a supervisão fornecida é inadequada e causa níveis aumentados de stresse. Neste sentido as equipes de enfermagem precisam ser estáveis e integrar enfermeiras experientes 


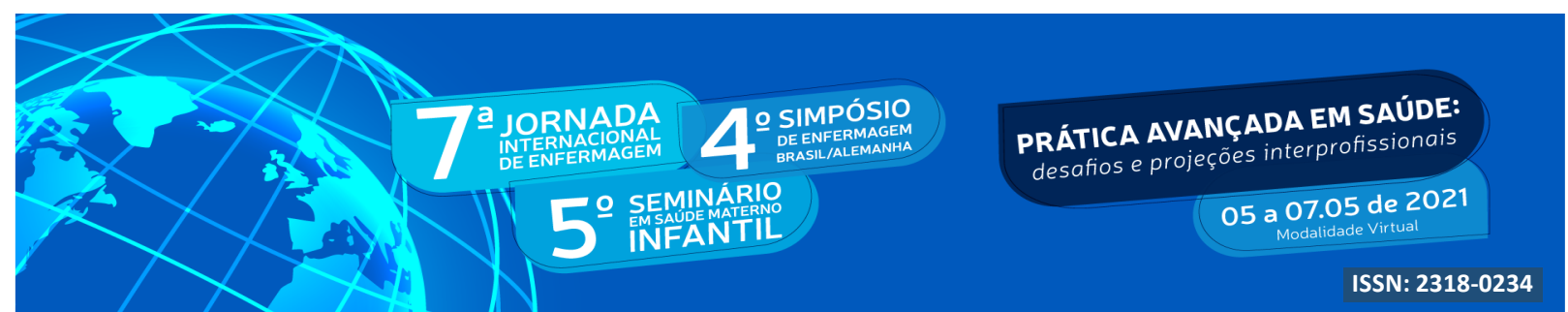

(com mais de dois anos de experiência na mesma enfermaria) que garantam a qualidade da interação dos novos profissionais (WILLMAN; BJURESÄTER, NILSSON, 2020).

A Duração do Processo de Integração, foi outro aspeto dificultador do processo, sendo o tempo de integração considerado insuficiente para se adaptarem e adquirirem confiança e segurança: “(...) no fim dos nove dias não me sentia preparada, ainda tinha muitas dúvidas e receios." E9; "O tempo de integração é curto (...) fica aquém das necessidades reais. Confesso que no final dos 15 dias não me sentia totalmente à vontade e segura para ficar como elemento numerário." E10. Willman, Bjuresäter e Nilsson (2020) também referem que é fundamental que a gestão hospitalar e os serviços criem programas de integração que delimitem o tempo e os recursos adequados para integração dos enfermeiros recém-formados, com base nas suas necessidades de treino adicional, que varia em função do serviço.

\section{CONCLUSÃO}

Um dos objetivos do processo de integração é estimular a performance profissional dos novos enfermeiros, contribuindo para a eficácia da instituição. Algumas das vantagens, para os enfermeiros, resultantes de uma boa integração são a diminuição do stresse, frustração e conflito, o aumento da autoconfiança, do autodesenvolvimento, da satisfação pessoal e profissional. Decorrente das vivências do processo de integração das participantes no estudo identificaram-se fatores facilitadores e dificultadores do mesmo.

A identificação dos fatores dificultadores à integração, constituiu um aspeto relevante, na medida em que permite aos órgãos de gestão das instituições delinearem estratégias que possam minimizar os aspetos menos positivos, atender às necessidades identificadas e otimizar a operacionalização do processo.

Um aspeto importante no processo de integração é a duração. A duração é, normalmente, variável dependendo das necessidades imediatas e a longo prazo do serviço e do enfermeiro em integração. Contudo, deve permitir que o enfermeiro a integrar possa desenvolver as competências essenciais para o desempenho da sua atividade profissional. 


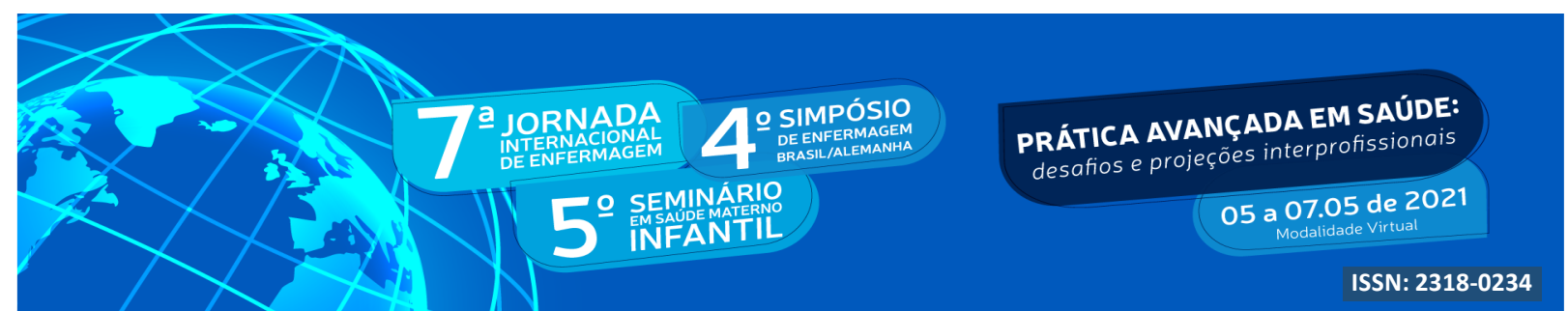

\section{REFERÊNCIAS}

AGGAR, C., et al. Australia's first transition to professional practice in primary care program for graduate registered nurses: a pilot study. BMC Nursing, v. 16, n. 14, p. 1-11, Mar. 2017. BARDIN, L. Análise de Conteúdo. $5^{\text {a }}$ ed. Lisboa: Edições 70, 2011.

INTERNATIONAL COUNCIL OF NURSES. Enfermeiros: Uma força para Mudar - Um Recurso Vital para a Saúde: Dia Internacional do Enfermeiro 2014. Edição Portuguesa: Ordem dos Enfermeiros, maio 2014.

INTERNATIONAL COUNCIL OF NURSES. International workforce forum calls for urgent action from governments to address global nursing shortage. Geneva, Switzerland, Mar. 2019. Retrieved from https://www.icn.ch/news/icn-inter natio nal-workf orce-forum-calls-urgentaction-gover nments-addre ss-global-nursing

MARRINER, A. Guide to nursing management and leadership. $8^{\mathrm{a}}$ ed., Mosby Elsevier, 2009.

OLIVEIRA, P. Auto-eficácia específica nas competências do Enfermeiro de cuidados gerais: perceção dos estudantes finalistas do Curso de Licenciatura em Enfermagem. 2010. Dissertação (Mestrado em Administração e Planificação da Educação), Universidade Portucalense Infante D. Henrique, Porto. 2010.

PINHEIRO, G. Supervisão colaborativa e desenvolvimento profissional em enfermagem. 2012. Dissertação (Mestrado em Supervisão), Universidade de Aveiro, Aveiro. 2012.

PIRES, R. et al. Estratégias de supervisão clínica: análise crítico-reflexiva das práticas. Revista Millenium, v. 2, n. 14, p. 47-55, jan. 2021.

SANTOS, M. Desenvolvimento de competências profissionais com a educação pelos pares. 2009. Dissertação (Mestrado em Ciências de Enfermagem), Instituto de Ciências Biomédicas Abel Salazar, Porto. 2009.

SOUZA, J. Motivação no Trabalho: uma análise dos dois fatores da Teoria Motivacional de Herzberg. Paraná: Universidade de Brasília, 2011.

WHITE, E.; WINSTANLEY, J. Clinical Supervision and the Helping Professions: An Interpretation of History. The Clinical Supervisor, vol. 33, n. 1, p. 3-25, June 2014.

WILLMAN, A.; BJURESÄTER, K.; NILSSON, J. Newly graduated reg-istered nurses' selfassessed clinical competence and their need for further training. Nursing Open, v. 7, n. 3, p. 720-730, Feb. 2020. 